years, show that those whose interest in lilies is practical and aesthetic, need, and desire, the specialized help of the geneticist, the physiologist and the pathologist.

\section{Scientia Genetica}

WIтн the object of stimulating the development of genetics in the Latin countries, a new journal, Scientia Genetica, is being launched under the direction of Prof. Carlo Jucci of the University of Pavia and with his colleague Prof. Adriano BuzzatiTraverso as its editor-in-chief. Though it is primarily intended to provide an appropriate medium for publication for geneticists in these particular countries, original papers from elsewhere will be welcomed so long as they are written in Italian, French, Spanish or Portuguese, and possess a strictly genetical interest. There is to be a special section for abstracts, reviews of recent books and for summaries of original papers dealing with animal and plant breeding (such papers will not be published in full). At the end of each year there will be given a complete bibliography of papers of genetical interest that have appeared in the scientific literature of the Latin countries, and from time to time there will be presented a critical review of some selected field. Geneticists will welcome this addition to the literature of their science. It undoubtedly supplies a need, and it may be expected to play a notable part in the inevitable advancement of genetics not only in the Latin countries but also in the world as a whole.

\section{Beneficial Insects}

IN 1922 the Ministry of Agriculture and Fisheries issued a small publication on "Beneficial Insects". It contained little-known information, written in a non-technical style, on those insects that are beneficial to the farmer, fruit-grower and gardener. During the sixteen years which have elapsed, this bulletin has passed through three editions and has been reprinted on five occasions. Knowledge of insects of this kind has greatly increased in the interval and the practical measures that can be taken to increase their usefulness have been extensively investigated. This new bulletin (No. 20 ; 1939) has been entirely re-written by Dr. W. R. Thompson and forms a useful nontechnical introduction to the subject. It is obtainable from His Majesty's Stationery Office, or through any bookseller, price $9 d$. net.

\section{Advanced Study at the University of Cambridge}

The University of Cambridge has recently published abstracts of ninety-one dissertations approved during the academic year 1937-38 for the Ph.D. (75), M.Sc. (11) and M.Litt (5) degrees. The abstracts are full enough (averaging about a page and a half) to give a fair idea of the substance of the dissertations. They may be roughly grouped as follows: the humanities 26, pure science 55, applied science 10 . The actual distribution according to faculties is : divinity 2, moral science 2, classics 3, English 4, modern and medieval languages 6, history 3, economics and politics 3, archæology and anthropo- logy 2, geography 1 , mineralogy and petrology 4, mathematics 8 , physics 6 , chemistry 14 , botany and zoology 15, biochemistry and physiology 8, agriculture 3, engineering 7 .

\section{North Pacific Earthquake}

AN earthquake of moderate intensity occurred on November 17, 1938, and its epicentre has been determined by the United States Coast and Geodetic Survey in co-operation with Science Service and the Jesuit Seismological Association as lat. $55^{\circ} \mathrm{N}$., long. $158^{\circ} \mathrm{W}$. It is estimated to have normal focal depth. This preliminary determination was made with the help of readings from the following stations : Georgetown, Fordham, Weston, Chicago, Ann Arbor, Ukiah, Victoria, San Juan, St. Louis, Tueson, Philadelphia, Williamstown, Butte, Bozeman, Honolulu, Manila, Sitka, Pasadena, College, Burlington, Huancayo and Kew. The epicentre is situated under the ocean bed to the south of the Alaska Peninsula, and is not far distant from the scene of the violent earthquake of November 10 , which was lat. $56^{\circ} \mathrm{N}$., long. $150^{\circ} \mathrm{W}$.

\section{National Physical Laboratory: Publications}

THE demand for the first issue of the "National Physical Laboratory Abstracts", which covered papers contributed by the Laboratory to the scientific and technical press during the year 1936, has proved its value to industry and has justified the recent issue of a similar pamphlet for the year 1937. The abstracts of papers in the present issue cover sixty-seven pages and on the average an abstract occupies a little less than half a page. They are arranged in order of subject: engineering, metallurgy, electricity and heat and general physics abstracts occupying 7-11 pages each and other subjects less. Both author and subject indexes are provided. The pamphlet may be purchased directly from H.M. Stationery Office, price $1 s$.

\section{Finney-Howell Research Fellowships}

Finney-Howell Research Fellowships have been renewed for the following: Dr. P. C. Aebersold, University of California, Berkeley; Margaret E. Boyland, Royal Cancer Hospital, London; Dr. Alma Howard, McGill University, Montreal ; Dr. Ll. M. Joshel, Harvard University; Dr. Ll. W. Law, Jackson Laboratory for Cancer Research, Bar Harbor, Maine; Dr. H. Lisco, Johns Hopkins Hospital, Baltimore; Dr. C. S. MeEuen, MeGill University; Dr. W. C. Merkel, Union Memorial Hospital, Baltimore. Fellowships for 1939 have been awarded to the following: G. M. Badger, of Melbourne, Australia, to work at the Royal Cancer Hospital, London; Dr. A. Kirschbaum, to work at Yale University; Dr. J. L. Melnick, to work at Yale University; Dr. J. F. Menke, to work at Stanford University Hospital ; Dr. J. L. Wood, to work at Harvard University; Dr. P. C. Zamecnik, to work under Dr. K. Linderström-Lang at the Carlsberg Laboratory, Copenhagen. Grants in aid have been awarded to Dr. R. D. Fowler and Dr. R. W. 